\section{MASTER}

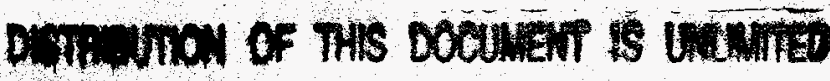

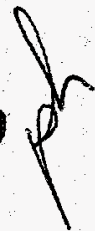

RECEIVED

Dex $16 \mathrm{mgl}$

OSTI

\title{
DATA RECONCILIATION STUDY OF TANK 241-AN-105 AT THE HANFORD SITE
}

\author{
William L. Kubic, Jr. \\ Gautam Pillay
}

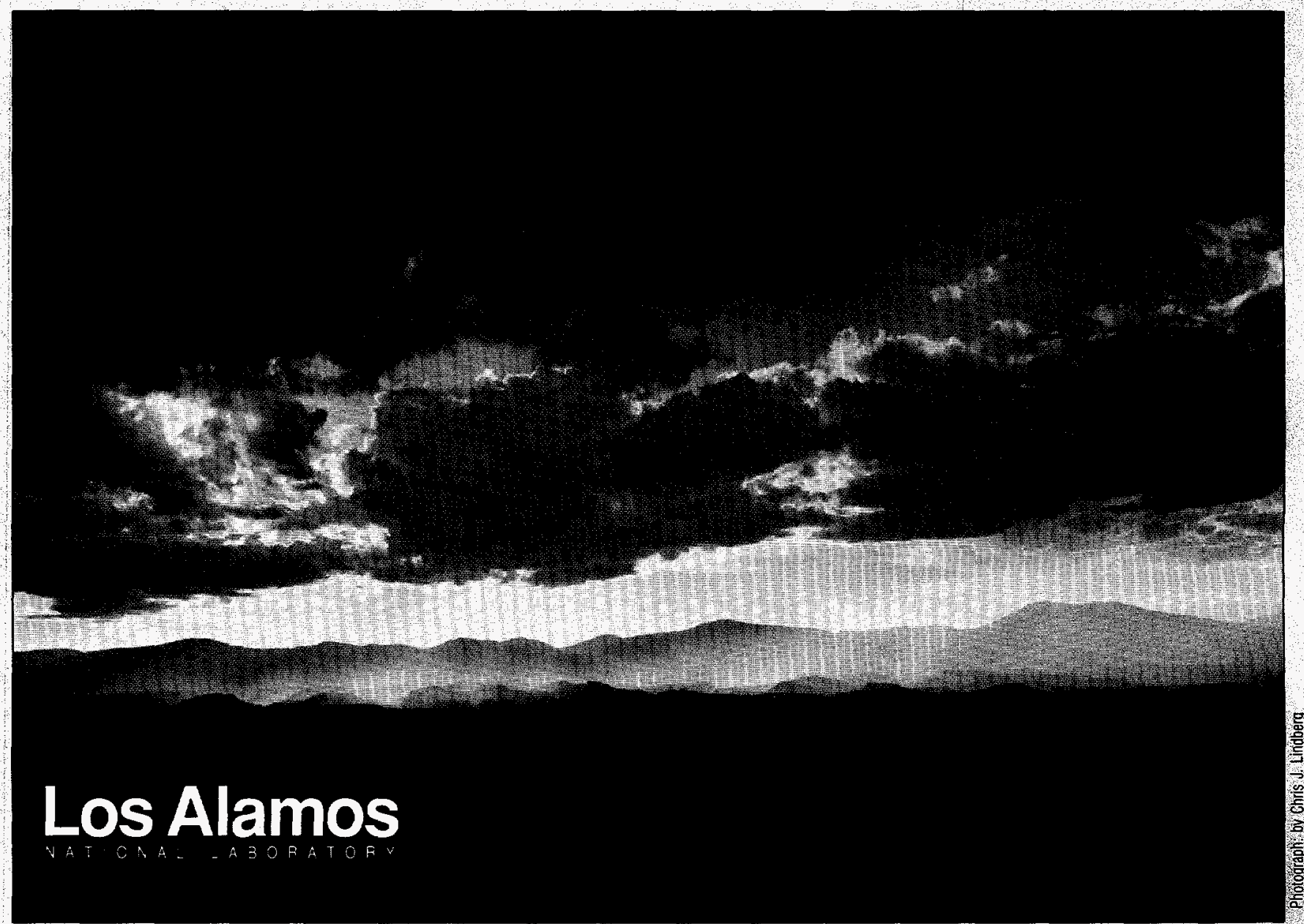

Los Alamos National Laboratory, an affirmative action/equal opportunity employer, is operated by the University of California for the U.S. Department of Energy under contract W-7405-ENG-36. By acceptance of this article, the publisher recognizes that the U.S. Government retains a nonexclusive, royalty-free license to publish or reproduce the published form of this contribution, or to allow others to do so, for U.S. Government purposes. The Los Alamos National Laboratory requests that the publisher identify this article as work performed under the auspices of the U.S. Department of Energy. Los Alamos National Laboratory strongly supports academic freedom and a researcher's right to publish therefore, the Laboratory as an institution 


\section{DISCLAIMER}

This report was prepared as an account of work sponsored by an agency of the United States Government. Neither the United States Government nor any agency thereof, nor any of their employees, makes any warranty, express or implied, or assumes any legal liability or responsibility for the accuracy, completeness, or usefulness of any information, apparatus, product, or process disclosed, or represents that its use would not infringe privately owned rights. Reference herein to any specific commercial product, process, or service by trade name, trademark, manufacturer, or otherwise does not necessarily constitute or imply its endorsement, recommendation, or favoring by the United States Government or any agency thereof. The views and opinions of authors expressed herein do not necessarily state or reflect those of the United States Government or any agency thereof. 


\section{DSECLAMIER}

Portions of this docoment may be illegible in electronic imsge prodnets. Inoges are produced from the best arailable original docomentert 
DATA RECONCILIATION STUDY OF TANK 241-AN-105 AT THE HANFORD SITE

\author{
by \\ William L. Kubic, Jr. \\ Gautam Pillay \\ Nuclear Systems Design and Analysis \\ Los Alamos National Laboratory \\ Los Alamos, New Mexico 87545
}

\begin{abstract}
The Project Hanford Management Contractor gave the Los Alamos National Laboratory Nuclear Systems Design and Analysis Group (TSA-10) the task of performing data reconciliation studies on flammable-gas watchlist tanks at the Hanford Site. This task is being performed in support of the flammable-gas programs at the Hanford Site and for closure of the flammable-gas unreviewed safety question. In our data reconciliation studies, we examine all available data from a global point of view. Our goal is to find an explanation, or conceptual model, of the tank behavior that is consistent with all available data. Our primary tool in this study of Tank 241-AN-105 is the maximum likelihood method of data reconciliation, which we have applied successfully to other tanks in the past. This method helps us (1) determine whether a model is consistent with the data and (2) obtain quantitative estimates that are consistent with the data.
\end{abstract}

A release of a flammable quantity of hydrogen in Tank 241-AN-105 is possible but unlikely at the current time. Any changes to the waste that could cause large releases would be accompanied by a measurable increase in the surface level of the waste. We also theorize that a significant increase in the waste temperature may signal a qualitative change in the behavior of the waste and an increase in the flammability hazard. 
DATA RECONCILIATION STUDY OF TANK 241-AN-105 AT THE HANFORD SITE

\subsection{INTRODUCTION}

The Project Hanford Management Contractor gave the Los Alamos National Laboratory Nuclear Systems Design and Analysis Group (TSA-10) the task of performing data reconciliation studies on flammable-gas watchlist tanks at the Hanford Site. This task is being performed in support of the flammable-gas programs at the Hanford Site and closure of the flammable-gas unreviewed safety question (USQ). This report summarizes our data reconciliation study of Tank 241AN-105.

Our study consists of an independent evaluation of the available data and an examination of these data from a global point of view. Our goal is to find an explanation, or conceptual model, of the tank behavior that is consistent with all available data. We do not attempt to include all details of the waste tank behavior in our conceptual model. Instead, we use simple models that enable us to understand the relationships among a diverse set of measurements. Our conceptual models, including our model of gas-release events (GREs), are based on material and volume balance relations.

There are several advantages to a consistent conceptual model of the tank.

- Although consistency with data does not prove that a model is correct, it is much easier to defend a safety analysis that is based on a consistent model.

- A conceptual model that is consistent with the data is useful for identifying changes to the waste that may result in additional hazards or increased risk. A bounding model based on worst-case data is not useful for predicting adverse changes.

- A consistent model may help identify measurable changes that indicate increased hazard or risk.

- With a consistent model, we can redundant data to obtain better estimates of important safety-related parameters such as retained gas volume.

Our primary tool in this study of Tank 241-AN-105 is the maximum likelihood method of data reconciliation. We have applied this method successfully to other tanks in the past.1,2,3 This method helps us (1) determine whether a model is consistent with the data and (2) obtain quantitative estimates that are consistent with the data. The basic steps in our analysis are to

1. compile and evaluate the available data,

2. develop conceptual models to explain the observed behavior, 
3. perform the maximum likelihood analysis, and

4. repeat the first three steps until a consistent conceptual model is obtained.

This report summarizes our analysis and results for Tank 241-AN-105.

\subsection{DATA}

Tank 241-AN-105 is an actively ventilated double-shell tank with a waste volume capacity of $\sim 1,160,000$ gal. This tank contains $\sim 1,130,000$ gal. of double-shell slurry. Major additions to Tank 241-AN-105 began in late 1982. Significant transfers to and from this tank occurred between 1981 and 1985. The waste inventory was removed in April 1986. The last major fill occurred in April 1986, when $1,130,000$ gal. of waste from the 85-3 evaporator campaign was added to a nearly empty tank. 4

\subsection{Waste Temperature}

We obtained waste temperature data from the TWINS data base on the World-Wide Web and from Ref. 5. The average waste temperature for 1997 is $38^{\circ} \mathrm{C}$. The standard deviation of this estimate is $1^{\circ} \mathrm{C}$. The waste was warmer when the tank was filled in 1985. The average waste temperature for 1985 was $47^{\circ} \mathrm{C}$. The standard deviation for this estimate is $2^{\circ} \mathrm{C}$. There have been no clear trends in the average waste temperature since the initial cooling period after the tank was filled. Between 1991 and 1994 , the average waste temperature increased $4.5^{\circ} \mathrm{C}$. Since 1994 , the average waste temperature has decreased $3^{\circ} \mathrm{C}$.

The temperature variation within the waste is relatively small. The minimum temperature is $\sim 34^{\circ} \mathrm{C}$, and the maximum temperature is $\sim 42^{\circ} \mathrm{C}$. The lowest temperature was measured at the bottom thermocouple location. The highest temperature was measured in the nonconvective (NC) layer $100 \mathrm{in}$. from the bottom of the tank. There is considerable variability in the temperature at the bottom thermocouple location. The temperature varies $\pm 4^{\circ} \mathrm{C}$ about the mean.

\subsection{Waste Composition}

We obtained waste composition data from two sources: supernatant liquid samples taken in 1985 and core samples taken in 1996.

Assays for two convective (C) layer samples taken in 1985 are given in Ref. 4 . The average of these samples is given in Table I. The assays do not report the concentrations of heavy metal ions such as iron, chromium, and so forth. Also, plutonium concentrations are not given. The measured hydroxide ion concentration was the same in both samples, so we use a standard deviation typical of other tanks. The concentrations of ${ }^{137} \mathrm{Cs}$ and ${ }^{90} \mathrm{Sr}$ were determined for only one sample. We use a standard deviation typical of other tanks for these isotopes. 
TABLE I

SUPERNATANT LIQUID SAMPLES TAKEN FROM TANK AN-105 IN 1985

\begin{tabular}{|c|c|c|c|}
\hline Chemical Species & Mean & Std Dev & Units \\
\hline & 49.0 & & \\
$\mathrm{H}_{2} \mathrm{O}$ & 3.0 & 12.6 & $\mathrm{wt.} \%$ \\
$\mathrm{OH}$ & 3.5 & $0.3^{*}$ & $\mathrm{~mole} / \mathrm{L}$ \\
$\mathrm{NO}_{3}$ & 1.7 & 1.0 & $\mathrm{~mole} / \mathrm{L}$ \\
$\mathrm{NO}_{2}$ & 1.3 & 1.0 & $\mathrm{~mole} / \mathrm{L}$ \\
$\mathrm{AlO}_{2}$ & 0.54 & 0.5 & $\mathrm{~mole} / \mathrm{L}$ \\
$\mathrm{CO}_{3}$ & 0.02 & 0.23 & $\mathrm{~mole} / \mathrm{L}$ \\
$\mathrm{SO}_{4}$ & 3.9 & 0.01 & $\mathrm{~mole} / \mathrm{L}$ \\
$\mathrm{TOC}^{* *}$ & 10.9 & 0.3 & $\mathrm{~g} / \mathrm{L}$ \\
$\mathrm{Na}$ & 613000 & 0.8 & $\mathrm{~mole} / \mathrm{L}$ \\
${ }^{137} \mathrm{Cs}$ & 4000 & $123000^{*}$ & $\mu \mathrm{Ci} / \mathrm{L}$ \\
${ }^{90} \mathrm{Sr}$ & $1000^{*}$ & $\mu \mathrm{Ci} / \mathrm{L}$ \\
\hline
\end{tabular}

*Standard deviation estimate based on data from other tanks.

**Total organic carbon.

Two core samples were taken from AN-105 in 1996. The chemical analyses of these samples is given in Ref. 6. These samples were cooled to ambient temperature and separated into two fractions: drainable liquid and slurry. The slurry is the waste that remains after drainable liquids have been removed. No solids were found in the core segments obtained from the $C$ layer of the tank. The slurry constitutes $49.1 \mathrm{wt} \%$ of the waste. The standard deviation for the fraction slurry in the waste is $1.5 \mathrm{wt} \%$, and this estimate is based on uncertainty in the layer thicknesses in the waste. The average compositions of the liquid and slurry samples are given in Table II. The concentrations of some chemical species are based on a single composite sample. The reproducibility of the analytical procedure on a single sample does not represent total uncertainty. Analysis of a single sample does not include variability in the tank or any uncertainty introduced by sample handling. Therefore, we assume a standard deviation typical of other tanks we have studied for these components.

\subsection{Density Data}

Waste density data are available from a variety of sources. The $\mathrm{C}$ layer density at ambient temperature was obtained from assays of samples taken during 1985.4 Liquid density at ambient conditions was obtained from the 1996 core samples. ${ }^{6}$ The average density of the sludge at ambient temperature also was obtained from the 1996 core samples. ${ }^{6}$ The crust in AN-105 is too thin to obtain meaningful density data from the core samples. Densities of the NC layer also have been estimated using $\mathrm{x}$-ray images of the retained gas sampler (RGS). ${ }^{7}$ The in situ densities of the C 
TABLE II

SUMMARY OF COMPOSITION DATA FOR THE 1996 CORE SAMPLES

\begin{tabular}{|c|c|c|c|c|c|c|}
\hline \multirow{2}{*}{$\begin{array}{l}\text { Chemical } \\
\text { Species }\end{array}$} & \multicolumn{3}{|c|}{ Average of Liquid Samples } & \multicolumn{3}{|c|}{ Average of Slurry Samples } \\
\hline & Mean & Std Dev & Units & Mean & Std Dev & Units \\
\hline $\mathrm{H}_{2} \mathrm{O}$ & 49.9 & 2.2 & wt. \% & 44.4 & 2.9 & wt. $\%$ \\
\hline $\mathrm{OH}$ & 3.4 & $0.7^{*}$ & mole/L & 1.4 & $0.3^{*}$ & mole $/ \mathrm{kg}$ \\
\hline $\mathrm{NO}_{3}$ & 2.7 & 0.9 & mole/L & 1.8 & 0.5 & mole $/ \mathrm{kg}$ \\
\hline $\mathrm{NO}_{2}$ & 2.7 & 1.0 & mole /L & 1.4 & 0.2 & mole $/ \mathrm{kg}$ \\
\hline $\mathrm{AlO}_{2}$ & 1.50 & 0.14 & mole/L & 0.85 & 0.10 & mole $/ \mathrm{kg}$ \\
\hline $\mathrm{CO}_{3}$ & 0.18 & $0.05^{*}$ & mole/L & 0.89 & 0.23 & mole $/ \mathrm{kg}$ \\
\hline $\mathrm{SO}_{4}$ & 0.013 & 0.006 & mole/L & 0.06 & 0.02 & mole $/ \mathrm{kg}$ \\
\hline TOC & 4.3 & 2.0 & $\mathrm{~g} / \mathrm{L}$ & 4.9 & 0.7 & $\mathrm{~g} / \mathrm{kg}$ \\
\hline $\mathrm{Na}$ & 10.7 & 0.6 & mole/L & 8.9 & 1.1 & mole $/ \mathrm{kg}$ \\
\hline Heavylons & 0.005 & 0.001 & mole/L & 0.055 & 0.035 & mole $/ \mathrm{kg}$ \\
\hline${ }^{137} \mathrm{Cs}$ & 474000 & $94800^{*}$ & $\mu \mathrm{Ci} / \mathrm{L}$ & 255000 & 57000 & $\mu \mathrm{Ci} / \mathrm{kg}$ \\
\hline${ }^{90} \mathrm{Sr}$ & 41 & $10^{*}$ & $\mu \mathrm{Ci} / \mathrm{L}$ & 23000 & 16000 & $\mu \mathrm{Ci} / \mathrm{kg}$ \\
\hline $\mathrm{Pu}$ & $0.51 * *$ & 0.03 & $\mu \mathrm{g} / \mathrm{L}$ & 66 & 47 & $\mu \mathrm{g} / \mathrm{kg}$ \\
\hline
\end{tabular}

*Standard deviation estimate based on data from other tanks.

**Upper bound estimate.

and NC layers were obtained with the ball viscometer. ${ }^{8}$ The densities obtained from $x$-ray images of the RGS and from the ball viscometer are bulk densities including the retained gas. The density data for Tank AN-105 are summarized in Table III.

TABLE III

DENSITY DATA FOR TANK AN-105

\begin{tabular}{|l|l|c|c|}
\hline \multicolumn{1}{|c|}{ Source } & \multicolumn{1}{|c|}{ Value } & $\begin{array}{c}\text { Mean Density } \\
\left(\mathrm{g} / \mathrm{cm}^{3}\right)\end{array}$ & $\begin{array}{c}\text { Std Dev } \\
\left(\mathrm{g} / \mathbf{c m}^{3}\right)\end{array}$ \\
\hline 1985 Waste Samples & C Layer Density w/o Gas & 1.43 & 0.15 \\
1996 Core Samples & Liquid Density & 1.41 & 0.04 \\
& Sludge Density w/o Gas & 1.57 & 0.04 \\
& NC Layer Density w/o Gas & 1.58 & 0.04 \\
RGS X-Ray Images & NC Layer w/Gas & 1.71 & 0.19 \\
& & 1.43 & 0.02 \\
Ball Viscometer & C Layer w/ Gas & 1.51 & 0.05 \\
\hline
\end{tabular}




\subsection{Waste Levels and Layer Thickness}

Three instruments have been used to measure level in Tank 241-AN-105: the manual tape, the Food Instrument Corporation (FIC) gauge, and the Enraf gauge. We obtained level data from the TWINS data base that is available on the WorldWide Web. The FIC gauge was used before August 1995, the manual tape was used from May 1995 until October 1996, and the Enraf gauge has been used August 1995. The FIC data are plotted in Fig. 1. This figure indicates that significant level growth occurred before 1989. The large drops that occurred on July 8, 1986, and January 1, 1987 correspond to flushing and recalibration of the FIC gauge. ${ }^{4}$

The initial waste level was 407.1 in.; the standard deviation for this estimate is 1 in. We estimate the initial rate of level growth after the last fill to be $0.0063 \mathrm{in} . / \mathrm{day}$, and the standard deviation for this estimate is $0.0007 \mathrm{in}$./day. Currently, there is no change in the average waste level. Before the FIC gauge was taken out of service, the average waste level was $410.5 \mathrm{in}$. The measured level fluctuated $\pm 2.5 \mathrm{in}$. about the mean. The maximum FIC gauge measurement was 413.3 in. The average waste level based on is $410.3 \mathrm{in}$. The measured level fluctuated $\pm 1 \mathrm{in}$. about the mean. The maximum Enraf gauge measurement was 411.5 in.

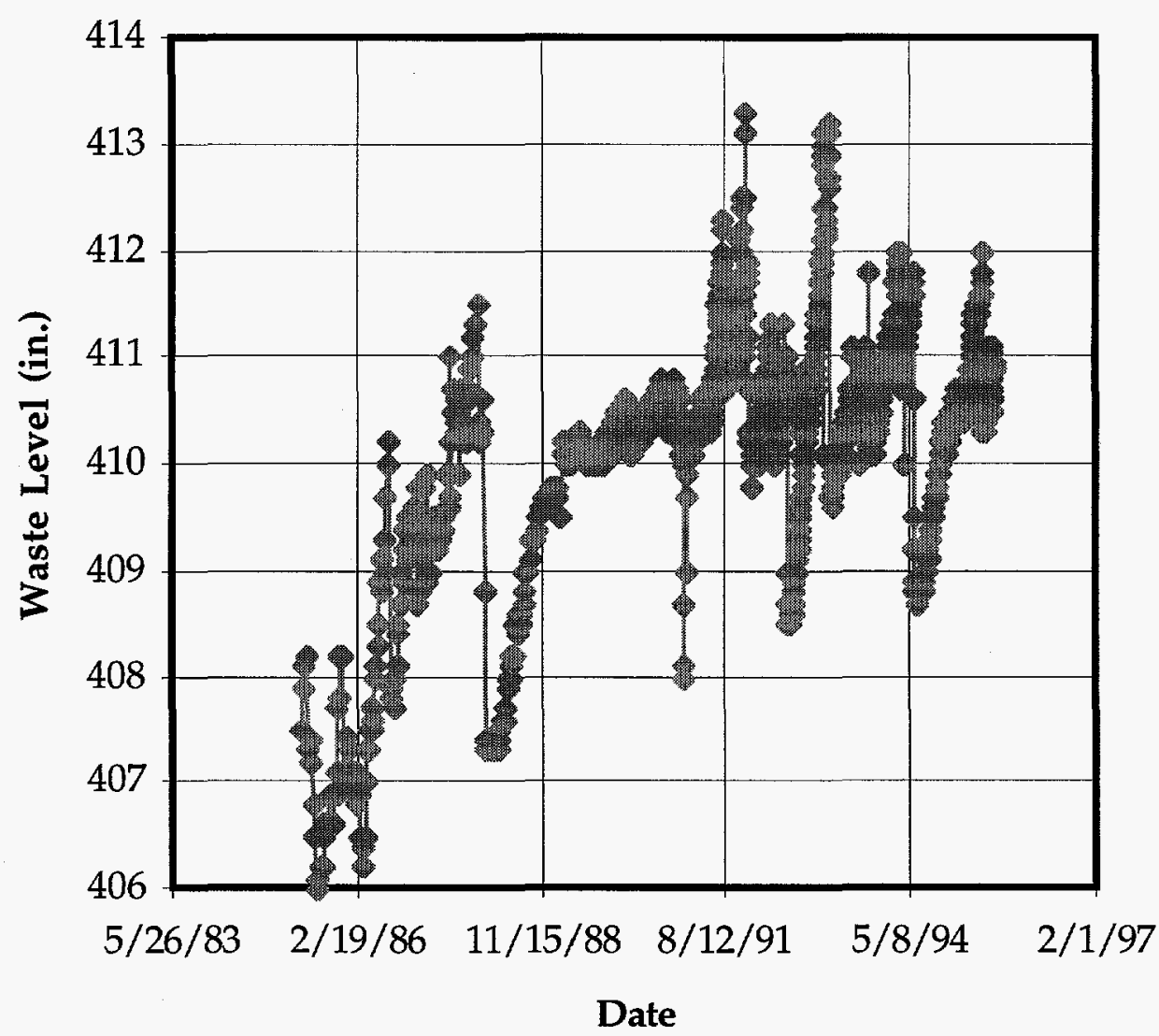

Fig. 1. Waste level as determined by the FIC gauge. 
The three level gauges are not the only source of waste level data. The temperature profile data indicates that the waste level is $<412 \mathrm{in}$. Based on the core sample from Riser 12A, the waste level is 412 in.; and based on the core sample from Riser 7B, the waste level is $410 \mathrm{in}$.

There is reasonable agreement among the various level measurements. We use the average of the measurements as the average waste level in our analysis. The average waste level is 410.7 in., and the standard deviation for this estimate is $1.0 \mathrm{in}$.

Photographs show that there is a crust on the surface of the waste. 4,5 Photographs in Ref. 4 show that there is some variability in the crust surface, but it is much more uniform than the crust in Tank 241-SY-101. The photographs in Ref. 5 indicate that there are significant holes in the crust. The temperature profile data indicate that the crust thickness is less than the thermocouple spacing. The thermocouple tree and waste level data indicate that the crust thickness $<48 \mathrm{in}$. The temperature profile obtained from the multifuctional instrument tree (MIT) and the waste level data indicate that the crust thickness is $<6 \mathrm{in}$. The core sample from Riser 12A indicates that the crust thickness is $2.5 \mathrm{in}$. The core sample from Riser 7B indicates that there is no crust, and photographs indicate that there may be a hole in the crust below Riser 7B. In this analysis, we do not attempt to quantify the crust thickness from data. We use 6 in. as an upper bound value of the crust thickness and assume that the standard deviation in the upper bound is $1 \mathrm{in.} \mathrm{to} \mathrm{account} \mathrm{for} \mathrm{uncertainty.}$

There are several methods of determining the thickness of the NC layer. The first method uses the temperature profile. We fit the temperature profile in the NC layer to a quadratic equation and determine the elevation at which the NC layer temperature equals the $C$ layer temperature. We obtained an NC layer thickness of 176 in. using this method. We used a similar method with the gas fraction data. We fit the NC layer gas fraction measurements obtained with the void fraction instrument ${ }^{8}$ to a quadratic equation. Because the $C$ layer contains very little void, we determine the NC layer thickness by extrapolating the gas fraction equation to zero. Based on the void profile from Riser 1B, the NC layer thickness is $168 \mathrm{in}$., and based on the void profile from Riser 16B, the NC layer thickness is 167 in. Finally, we used the core samples to determine NC layer thickness. Based on the amount of extruded slurry, the NC layer thickness is 164 in. at Riser 12A and Riser 7B.

All methods of determining the NC layer thickness are in reasonable agreement. Because the various estimates are based on data from different locations, it appears that the NC layer thickness is relatively uniform in AN-105. We use the average of these estimates in our analysis. The average NC layer thickness is $168 \mathrm{in}$. , and the standard deviation for this estimate is 5 in.

\subsection{Gas Fraction}

Gas measurements obtained using the void fraction instrument are given in Ref. 8. Based on a simple average of these data, the average gas fraction for the NC layer is 
$3.3 \mathrm{vol} \%$. These results are slightly different from the average given in Ref. 8 because (1) Ref. 8 includes the RGS data in the average and (2) the average is based on a three-layer model of the NC layer. The average gas fraction for the convective layer is reported to be $0.2 \mathrm{vol} \% .8$ Our evaluation of the void fraction instrument indicates that it cannot reliably detect gas fractions $<2.0 \mathrm{vol} \%$; 9 therefore, we interpret the low gas fraction measurement to mean that the gas fraction is $<2.0 \mathrm{vol} \%$.

Our theoretical analysis of the gas fraction instrument indicates that there is $\pm 2.0 \mathrm{vol} \%$ error in the void measurement as a result of a difficulties in capturing bubbles. ${ }^{9}$ Based on the scatter in the data, the standard deviation for the void fraction in the NC layer is $1.8 \mathrm{vol} \%$ and the standard deviation of the mean is $0.4 \mathrm{vol} \%$. We are interested primarily in the average void fraction in the NC layer; therefore, we base the uncertainty on the standard deviation in the mean. Because of accuracy problems with the device at low void fractions, we use our theoretical estimate of uncertainty for the $C$ layer. Therefore, we use $1.0 \mathrm{vol} \%$ for the standard deviation of the C-layer void fraction.

\subsection{Dome Space Gas Measurements}

Grab sample data are available for Tank AN-105.10 These samples are summarized in Table IV. Because of the large variability, we use a lognormal distribution to describe the uncertainty in the background hydrogen concentration. The median background hydrogen concentration is $85 \mathrm{ppm}$, and the standard deviation of the natural logarithm of hydrogen concentration is 0.54 .

In our analysis, we express the nitrous oxide and methane concentrations as a ratio to hydrogen. The nitrous-oxide-to-hydrogen ratio is 0.185 , and the standard deviation is 0.007 . We used the data from the May 1996 GRE to determine the methane-to-hydrogen ratio. The methane concentration was corrected for the $2 \mathrm{ppm}$ of methane that occur naturally in air. 11 The methane-to-hydrogen ratio is 0.012 , and the standard deviation is 0.012 .

\subsection{Retained Gas Sampler}

The RGS is an indirect method of determining the retained gas volume and composition. ${ }^{7}$ The RGS is a sealed sampler that is used during normal core sampling operations. When a retained gas sample is obtained, it is taken to the laboratory and extruded into the gas extraction apparatus. A vacuum pump is used to extract the gas from the waste sample. The following data are produced by this process.

- The gas composition and pressure in the collector canisters.

- The pressures and temperatures in the collector canisters as function of time while the extraction is being performed. 
TABLE IV

GAS GRAB SAMPLES FROM THE DOME OF TANK AN-105

\begin{tabular}{|c|c|c|c|c|}
\hline Date & $\mathbf{H}_{\mathbf{2}} \mathbf{( p p m )}$ & $\mathbf{N}_{\mathbf{2}} \mathbf{O}$ (ppm) & $\mathbf{C H}_{\mathbf{4}} \mathbf{( p p m )}$ & TankCondition \\
\hline $11 / 2 / 94$ & 101 & 19 & $<10$ & Baseline \\
$11 / 9 / 94$ & 220 & 31 & $<10$ & Baseline \\
$11 / 16 / 94$ & 96 & 20 & $<10$ & Baseline \\
$11 / 22 / 94$ & 98 & 20 & $<10$ & Baseline \\
$11 / 30 / 94$ & 114 & 20 & $<10$ & Baseline \\
$12 / 7 / 94$ & 69 & 14 & $<10$ & Baseline \\
$12 / 14 / 94$ & 173 & 26 & $<10$ & Baseline \\
$2 / 29 / 96$ & 40 & 8 & $<10$ & Baseline \\
$2 / 29 / 96$ & 66 & 11 & $<10$ & Baseline \\
$3 / 27 / 96$ & 40 & 8 & $<10$ & Baseline \\
$3 / 27 / 96$ & 59 & 8 & $<10$ & Baseline \\
$5 / 30 / 96$ & 49 & 10 & $<10$ & Baseline \\
$5 / 30 / 96$ & 134 & 27 & $<10$ & Baseline \\
$8 / 23 / 95$ & $<5$ & $<5$ & 2 & GRE \\
$8 / 23 / 95$ & $<5$ & $<5$ & 3 & GRE \\
$5 / 30 / 96$ & 4,200 & 860 & 60 & GRE \\
$5 / 30 / 96$ & 10,700 & 2000 & 110 & GRE \\
& & & & \\
\hline
\end{tabular}

- The pressures and temperatures in the extractor volume as function of time while the extraction is being performed. The extractor volume contains the waste sample.

- The moles of ammonia in the ammonia canisters.

- The volumes of the collector canisters and system components.

The RGS data for AN-105 are difficult to interpret. We performed a detailed analysis of the RGS data from Tank 241-AW-101 (AW-101) using a maximum-likelihood data reconciliation. 3,12 Based on the results of the RGS study, we have found that it is possible to obtain reasonable results with a much simpler analysis. The quantities of interest are the moles of hydrogen, nitrogen, nitrous oxide, and methane per unit volume of waste; ammonia concentration in the liquid; and the amount of air entrained in the sample. The data that we use in this study and the methods of obtaining these data are as follows.

- The moles of hydrogen, nitrogen, nitrous oxide, and methane per unit volume of waste. These estimates include dissolved gas as well as any air that has contaminated the sample. We estimate these quantities from the 
composition and pressure of the collector canisters, which is the method used in Ref. 7. We found that this simple method of estimating the amounts of slightly soluble gases is in good agreement with the maximum likelihood results.

- The ammonia partial pressure at ambient temperature. The ammonia partial pressure is estimated from the ammonia canister results. The quantity of interest, the ammonia concentration in the liquid, can be determined from ammonia partial pressure and Henry's law. The average ammonia concentration in the liquid obtained from maximum likelihood analysis of the AW-101 RGS data is 0.104 mole/L; the standard deviation is $0.022 \mathrm{~mole} / \mathrm{L}$. If we simply use the ammonia partial pressure data and Henry's law, we obtain an ammonia concentration of 0.110 mole/ $\mathrm{L}$ and a standard deviation of 0.034 mole/L. There is good agreement between the two results, although the simpler method has greater uncertainty.

- Upper and lower bounds on air entertainment. We express air entrainment in terms of moles/liter of waste. The presence of oxygen and nitrogen in the samples indicates that the waste has been contaminated by air. Oxygen reacts with the waste, ${ }^{13}$ so less oxygen is measured than was entrained with the air. If we calculate the amount of air entrainment assuming no oxygen reacts, we obtain a lower bound. The air in the drill string may be rich in argon as a result of the argon purge. Therefore, the amount of argon in the sample may be greater than the argon entrained with air. If we calculate the amount of air entrainment assuming no argon purge, we obtain an upper bound. The amount of nitrogen in the sample also represents an upper bound to air entertainment. We use the minimum upper bound in this analysis.

The RGS data are summarized in Table V. The values for slightly soluble gases are averages for the $C$ and NC layers. The ammonia partial pressure is an average for the entire tank. Because the $C$ layer may not be saturated with dissolved gas when the samples are taken, we regard the results for the $C$ layer as lower bound values.

The estimates of the uncertainties for the gases in the NC layer and the ammonia partial pressure at $24^{\circ} \mathrm{C}$ are based on the observed scatter in the data. There was only one RGS sample from the C layer, and therefore, we could not estimate the standard deviation from scatter in the data. We considered two factors in estimating the uncertainty for the C-layer sample: sample analysis errors and bubble capture uncertainty. Abbott and Unal determined that there was uncertainty as to whether a given bubble is captured by the void fraction instrument. ${ }^{9}$ This source of error translates into uncertainty in the measured void fraction. The phenomena that led to bubble capture uncertainty in the void fraction instrument also affected the RGS, and therefore, bubble capture is also a source of uncertainty for the RGS. We assume that the standard deviation for bubble capture uncertainty in the Clayer is 
$1.0 \mathrm{vol} \%$, which is the same as for Abbott and Unal's estimate for the void fraction instrument. The uncertainties in the RGS results are given in Table V.

TABLE V

SUMMARY OF RETAINED GAS SAMPLER DATA

\begin{tabular}{|c|c|c|}
\hline Quantity & Best Estimate & Std Dev \\
\hline \multicolumn{3}{|l|}{ Convective Layer } \\
\hline $\mathrm{H}_{2}(\mu \mathrm{mole} / \mathrm{L})$ & 72 & 13 \\
\hline $\mathrm{N}_{2} \mathrm{O}(\mu \mathrm{mole} / \mathrm{L})$ & 68 & 11 \\
\hline $\mathrm{N}_{2}(\mu \mathrm{mole} / \mathrm{L})$ & 440 & 110 \\
\hline $\mathrm{CH}_{4}(\mu \mathrm{mole} / \mathrm{L})$ & 3.6 & 1.0 \\
\hline Upper Bound $\mathrm{N}_{2}$ from Air $(\mu$ mole $/ \mathrm{L})$ & 280 & 60 \\
\hline Lower Bound $\mathrm{N}_{2}$ from Air $(\mu \mathrm{mole} / \mathrm{L})$ & 280 & 80 \\
\hline \multicolumn{3}{|l|}{ Nonconvective Layer } \\
\hline $\mathrm{H}_{2}(\mu \mathrm{mole} / \mathrm{L})$ & 2340 & 1090 \\
\hline $\mathrm{N}_{2} \mathrm{O}(\mu \mathrm{mole} / \mathrm{L})$ & 570 & 240 \\
\hline $\mathrm{N}_{2}(\mu$ mole $/ \mathrm{L})$ & 1200 & 300 \\
\hline $\mathrm{CH}_{4}(\mu \mathrm{mole} / \mathrm{L})$ & 26 & 11 \\
\hline Upper Bound $\mathrm{N}_{2}$ from Air $(\mu \mathrm{mole} / \mathrm{L})$ & 320 & 60 \\
\hline Lower Bound $\mathrm{N}_{2}$ from Air $(\mu \mathrm{mole} / \mathrm{L})$ & 280 & 80 \\
\hline $\mathrm{NH}_{3}$ Partial Pressure at $24^{\circ} \mathrm{C}(\mathrm{atm})$ & 0.0063 & 0.0005 \\
\hline
\end{tabular}

\subsection{Gas Release Events}

Small GREs have been observed in Tank AN-105. The standard hydrogen monitoring system (SHMS) detected GREs on August 21, 1995, and May 30, 1996. The peak dome hydrogen concentrations were 17,000 ppm for the August 1995 GRE and $\sim 14,500 \mathrm{ppm}$ for the May $1996 \mathrm{GRE}$. The level data indicate that GREs in AN105 are small compared with those in Tank 241-SY-101. The largest observed level drop in AN-105 is 2.5 in. ${ }^{14}$ GREs in SY-101 result in level drops between 5 in. and 13 in. 15

The GREs in AN-105 appear to be small rollovers similar to those that occur in SY101. Temperature profile data indicates that significant mixing occurs during some GREs. Fig. 2 shows the temperature profile in AN-105 before and after the May 1996 GRE. The change in temperature profile is similar to changes observed during GREs in SY-101. 


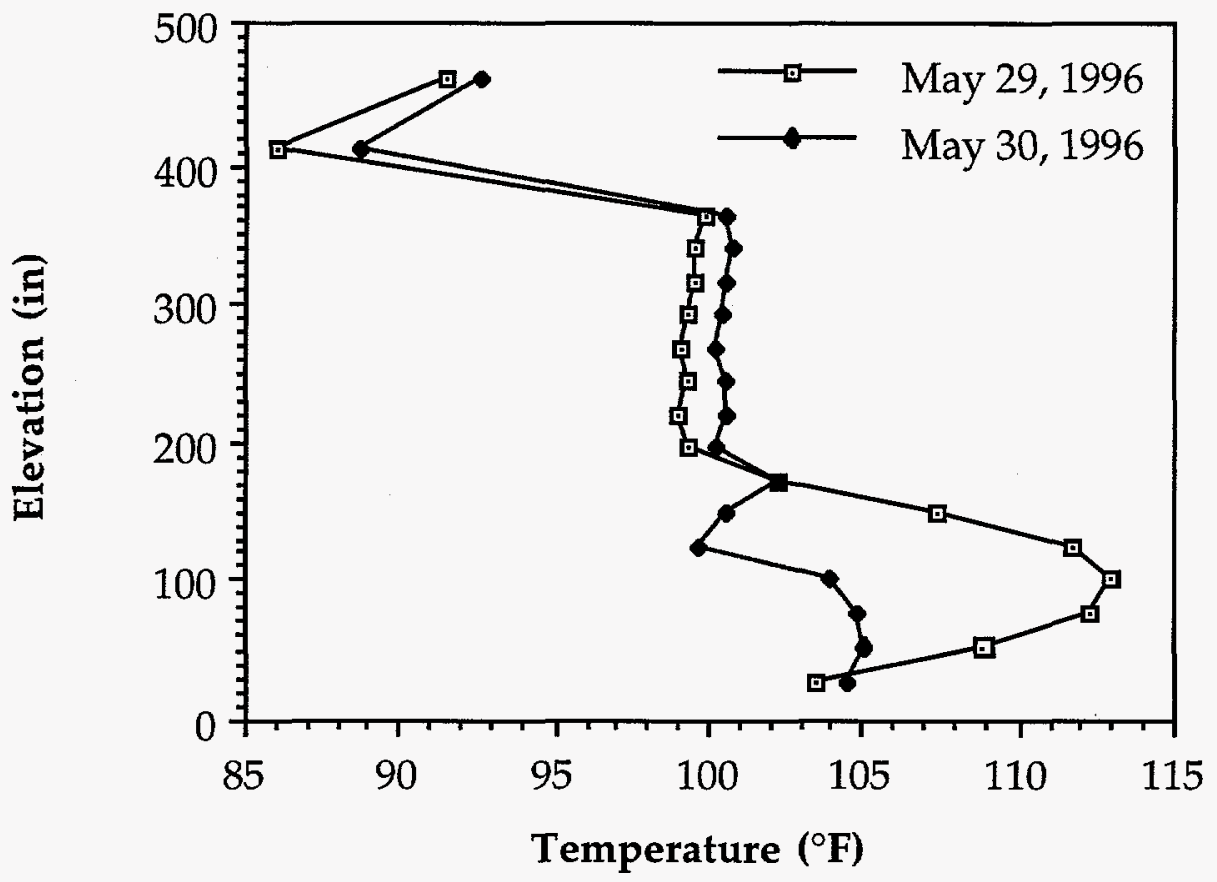

Fig. 2. Temperature profile data for AN-105 from May 1996.

Although Fig. 2 shows that the May 1996 GRE produced a large change in the temperature profile, we do not believe that GREs in AN-105 involve the entire NC layer. Thermal balance calculations indicate that $\sim 27 \%$ of the NC layer was involved in the GRE. Data from other GREs also indicates that only part of the NC layer is involved in GREs. The August 1995 GRE produced a small increase in the C layer temperature, but there was no significant change in the NC layer temperature profile, indicating that the release did not disturb the NC layer at the thermocouple location. Thermal balance calculations indicate that $\sim 24 \%$ of the NC Layer participated in the August 1995 event. Temperature profile data also indicate that GREs have occurred that only disturbed the upper portion of the NC layer. ${ }^{14}$

It is difficult to determine when a GRE occurs without SHMS data because the level drops are small and GREs may not always disturb the waste at the thermocouple tree location. However, there are no SHMS data and only limited temperature data before September 1994. Therefore, we must rely on level data to determine when GREs occurred before September 1994, but a review of level data may not be a reliable method of identifying GREs. Even in SY-101, level drop was not a sufficient criterion for determining whether a GRE had occurred. Other confirmatory data were required before an intrusion window was opened in SY-101.15 
We reviewed the level data from January 1, 1990, through July 1997 to determine when significant level drops occurred. We identified 12 significant level drops that cannot be attributed to flushing the FIC gauge or breaking of a stalactite on the FIC. 14 The significant level drops are listed in Table VI. Temperature data and SHMS data indicate that at least four of these significant level drops were GREs. Whether the other eight significant level drops are GREs is uncertain.

\section{TABLE VI}

SIGNIFICANT LEVEL DROPS IN TANK AN-105 SINCE JANUARY 1, 1990

\begin{tabular}{|c|c|l|}
\hline Date & Level Drops (in.) & \multicolumn{1}{|c|}{ Independent Verification } \\
\hline $7 / 19 / 91$ & -1.2 & \\
$11 / 14 / 91$ & -1.8 & \\
$12 / 8 / 91$ & -1.1 & \\
$4 / 13 / 92$ & -1.1 & \\
$7 / 5 / 92$ & -2.3 & Temperature Change \\
$9 / 26 / 92$ & -0.8 & \\
$1 / 22 / 93$ & -0.8 & \\
$9 / 18 / 93$ & -0.8 & \\
$5 / 16 / 94$ & -2.5 & Temperature Change \\
$8 / 21 / 95$ & -1.3 & SHMS Data \\
$5 / 30 / 96$ & -0.8 & Temperature Change, SHMS Data \\
$4 / 5 / 97$ & -0.5 & \\
& & \\
\hline
\end{tabular}

Assuming that the all of the significant level drops are GREs, the average time between GREs is 190 days, and the average size of the level drops is 1.3 in. The average rate of level growth between GREs is

$$
r_{\text {growth }}=\frac{\mu_{\delta \mathrm{z}}}{\mu_{\delta \mathrm{t}}},
$$

where $\mu_{\delta \mathrm{z}}$ is the average level drop and $\mu_{\delta \mathrm{t}}$ is the average time between events. The average rate of level rise is $0.0068 \mathrm{in}$./day and the standard deviation for this estimate is $0.0022 \mathrm{in}$./day.

\subsection{Waste Compressibility}

The change in waste level with respect to changes in barometric pressure is a measure of compressibility of the waste. Whitney analyzed data for level vs barometric pressure. ${ }^{16}$ The compressibility data show no clear trend with time. To determine if there have been any long-term changes in the waste compressibility, 
we used a t-test to compare the compressibility before and after 1989. We found that there is statistically significant difference in the mean compressibility for these two periods. This result is not surprising because significant level growth occurred before 1989. There have been no trends in the level since 1989. Although there are fluctuations as a result of GREs, the average waste level has remained constant.

Because the average waste level is not changing with time, the average waste compressibility is characteristic of the average gas inventory in the waste. Based on the compressibility data between 1991 and 1995, the average waste compressibility is $-0.12 \mathrm{in}$./in. $\mathrm{Hg}$; and the standard deviation in the mean is $0.03 \mathrm{in} . / \mathrm{in} . \mathrm{Hg}$.

\subsection{Ventilation Flow Rate}

Pre-1995 ventilation data are given in Ref. 5. These data show that there is considerable variability in the ventilation flow rate. Because of the large variability, we use a lognormal distribution to describe the uncertainty in the ventilation flow rate. Based on data from 1990 through 1994, the median ventilation flow rate is $93 \mathrm{scfm}$. The standard deviation of the natural logarithm of ventilation flow is 0.86 .

\subsection{MODELS}

Section 2 contains a summary of the waste tank data. These quantities are not independent. They are constrained by the physics of the system. For example, the electroneutrality constraint implies that the total charge of the cations must equal the total charge of the anions. Hence, the sodium ion concentration cannot be independent of the concentrations of the negative ions. These physical constraints abound, but they may be more complex than a simple charge balance.

This data reconciliation study uses these physical constraints to develop a global understanding of the data. These physical constraints are the system model, or in this case, a collection of models. This section summarizes the models we used in our analysis.

\subsection{Waste Tank Inventory}

Many of the physical constraints on the waste are material balances that arise from the principal of conservation of mass. To exploit the material balance relations, we must establish the waste tank inventory. If we establish the inventory, we can use material balance calculations to determine the composition of waste samples, densities, and so forth. Gas generation rate and composition are also functions of the inventory. Waste inventory is the common factor underlying all of the data.

To avoid confusion, we must clarify one aspect of our analysis method before describing our models. We do not start with the core sample data and calculate the waste inventory as was done in the tank characterization report. ${ }^{6}$ Instead, we start by assuming parameters such as overall waste composition, total waste volume, and 
so forth; then we calculate the sample compositions, densities, and other measured parameters. The maximum likelihood analysis is used to find the inventory that is most consistent with all of the data.

\subsubsection{Representing Waste Tank Inventory}

The waste composition in AN-105 is complex, and it is not uniform throughout the tank. It is impractical to fully characterize the tank contents, so we use a simplified model to represent the waste inventory.

Our simplified inventory model uses three layers to represent the waste.

- The slurry layer, which is found at the bottom of the tank. It is called the NC (nonconvective) layer because the temperature profile data indicate that there is little mixing in this layer.

- The middle layer, which is a liquid-like layer called the $C$ (convective) layer because temperature profile data indicate that some mixing occurs in this layer. The $C$ layer may contain some suspended solids.

- The top layer, which is the crust. It is a slurry layer or saltcake that floats on the surface of the waste.

We assume that each layer is uniform in composition, thickness, and temperature. The overall inventory in each layer is more important in our analysis than the distribution of materials with in a given layer. Therefore, the assumption that each layer is uniform is adequate for our analysis.

We represent waste composition using 16 components: water, sodium hydroxide, sodium nitrate, sodium nitrite, sodium aluminate, sodium carbonate, sodium sulphate, soluble organic material, insoluble organic material, heavy salt, ammonia, ${ }^{137} \mathrm{Cs},{ }^{90} \mathrm{Sr}$, and plutonium. Soluble organic material is a pseudocomponent representing organic salts such as sodium formate and sodium acetate that are completely dissolved in the liquid. We use sodium acetate to represent the soluble organic material. Insoluble organic material is a pseudocomponent representing organic salts such as sodium oxalate with negligible solubility in the waste. We use sodium oxalate to represent insoluble organic material. Heavy salt is a pseudocomponent representing salts of iron, chromium, calcium, and so forth with negligible solubility. The molecular weight and density of heavy salt is not known. Based on the possible compounds included in this pseudocomponent, the molecular weight should be between $70 \mathrm{~g} /$ mole and $250 \mathrm{~g} / \mathrm{mole}$; and the density should be between $2.3 \mathrm{~g} / \mathrm{cm}^{3}$ and $9.0 \mathrm{~g} / \mathrm{cm}^{3}$.

The parameters that we use to specify inventory in our model are 
- overall waste composition,

- degassed waste volume,

- thicknesses of the NC layer and crust,

- solids fraction in the NC layer and crust, and

- volume fraction gas bubbles in each layer.

\subsubsection{Solubility Calculations}

Solubility calculations are an important part of our inventory and material balance calculations. The solubility calculations enable us to determine the liquid composition, solids composition, and solids fraction. These quantities are needed to establish the liquid and solids inventory in each layer. Establishing the inventory of each layer enables us to determine the overall composition of a core segment. The solubility model also enables us to determine the change in liquid and solids compositions when core samples are cooled to ambient temperature. These calculations give the composition of the drainable liquid and the amount of solids in the sample.

We use a solubility model that is based on Meissner's model of aqueous solutions of strong electrolytes. ${ }^{17}$ This model was calibrated to waste composition data from Tank 241-SY-101, and we used this model for our data reconciliation this tank. ${ }^{2} \mathrm{We}$ have made two improvements to this model for this analysis. First, we base our estimate of strontium solubility on strontium carbonate rather than strontium hydroxide. Second we included the heptahydrated form of sodium carbonate as a possible solid phase.

\subsubsection{Density Calculations}

Densities are measured quantities as well as parameters needed for determining the liquid and solids inventory in each layer. Determining density is relatively straightforward. We estimated the liquid density using a mixing rule described in Ref. 18. This mixing rule enables us to estimate liquid density from composition. Unknown parameters in this model were calibrated to data from Tank 241-SY-101. ${ }^{2}$ The average densities of the solids and the various layers are determined using a weighted average:

$$
\frac{1}{\rho_{s}}=\sum_{i=1}^{n_{s}} \frac{w_{i}}{\rho_{i}},
$$

where

$\rho_{\mathrm{s}}=$ average solids density,

$w_{i}=$ weight fraction of $i$ in the solids, and

$\rho_{i}=$ density of solid crystal $i$. 
The bulk density of a slurry with no gas bubbles is

$$
\rho_{\text {slurry }}=\phi_{\mathrm{s}, \mathrm{ng}} \cdot \rho_{\mathrm{s}}+\left(1-\phi_{\mathrm{s}, \mathrm{ng}}\right) \cdot \rho_{\mathrm{L}},
$$

where

$$
\begin{aligned}
\rho_{\text {slurry }} & =\text { average slurry density } \\
\phi_{\mathrm{S}, \mathrm{ng}} & =\text { volume fraction solids with no gas, and } \\
\rho_{\mathrm{L}} & =\text { liquid density }
\end{aligned}
$$

The bulk density of a slurry with gas bubbles is

$$
\rho_{\text {bulk }}=\left(1-\phi_{\mathrm{g}}\right) \cdot \rho_{\text {slurry }}
$$

where

$$
\begin{aligned}
\rho_{\text {bulk }} & =\text { bulk density of a slurry with gas bubbles, and } \\
\phi_{\mathrm{g}} & =\text { volume fraction gas bubbles in the slurry. }
\end{aligned}
$$

We calculate the densities of waste samples at ambient temperature taking into account the solubility, and we assume that there are no gas bubbles in these samples. To predict the results of the $x$-ray images of the RGS and the densities obtained using the ball viscometer, we calculate the densities at the in situ temperature including retained gas bubbles.

\subsubsection{Stability Constraints}

The waste configuration in AN-105 implies that there are several constraints on density and gas fraction. The crust floats, which implies that the bulk density of the crust including gas must be less than the bulk density of the $C$ layer. The RaylieghTaylor model of GREs implies that the bulk density of the NC layer, including gas, must be greater than or equal to the bulk density of $C$ layer. 19 Otherwise a GRE would occur.

A significant volume of free bubbles cannot be retained in the $\mathrm{C}$ layer. For there to be a significant gas fraction in the $C$ layer, bubbles must be attached to particles and the bulk density of the particle-bubble cluster must be less than the liquid density. Otherwise, the cluster would float to the surface. This constraint of the density of the particle-bubble cluster implies that there is a constraint on the gas fraction in the $\mathrm{C}$ layer. This constraint is given by the following inequality:

$$
\phi_{\mathrm{g}} \leq \phi_{\mathrm{s}} \cdot\left(\frac{\rho_{\mathrm{s}}}{\rho_{\mathrm{L}}}-1\right),
$$


where

$$
\begin{aligned}
& \phi_{\mathrm{g}}=\text { volume fraction gas, } \\
& \phi_{\mathrm{s}}=\text { volume fraction solids, } \\
& \rho_{\mathrm{s}}=\text { solid density, and } \\
& \rho_{\mathrm{L}}=\text { liquid density }
\end{aligned}
$$

\subsubsection{Radioactive Decay and Radiolysis of Nitrate and Nitrite}

To relate the current waste inventory to waste samples taken in the past, we must account for the radioactive decay of ${ }^{137} \mathrm{Cs}$ and ${ }^{90} \mathrm{Sr}$ and the radiolytic decomposition of nitrate and nitrite ions.

The past inventories of ${ }^{137} \mathrm{Cs}$ and ${ }^{90} \mathrm{Sr}$ are easy to obtain. Past inventories are determined from the following equation:

$$
C i_{\text {past }}=C i_{\text {present }} \cdot \mathrm{e}^{\mathrm{k} \cdot \mathrm{t}},
$$

where

$\mathrm{Ci}_{\text {past }}=$ past isotope inventory,

$$
\begin{aligned}
\mathrm{Ci}_{\text {present }} & =\text { current isotope inventory, } \\
\mathrm{k} & =\text { rate constant for decay, and } \\
\mathrm{t} & =\text { time. }
\end{aligned}
$$

The rate constant for decay is determined from the half-life of the isotope. The values of $\mathrm{k}$ are $0.023 / \mathrm{yr}$ for ${ }^{137} \mathrm{Cs}$ and $0.024 / \mathrm{yr}$ for ${ }^{90} \mathrm{Sr}$.

We represent the radiolytic decomposition of nitrate and nitrite by the following reactions: 20

$$
\mathrm{NO}_{3}^{-} \stackrel{\mathrm{rad}}{\longrightarrow} \mathrm{NO}_{2}^{-} \stackrel{\mathrm{rad}}{\longrightarrow} \mathrm{OH}^{-}+\mathrm{N}_{2}, \mathrm{~N}_{2} \mathrm{O}, \mathrm{NH}_{3} \text {, etc. . }
$$

We use the following model to describe the decomposition of nitrate and nitrite:

$$
\frac{\mathrm{dC}_{\text {nitrate }}}{\mathrm{dt}}=-\mathrm{G}_{\text {nitrate }} \cdot \mathrm{E} \cdot \mathrm{C}_{\text {nitrate }}
$$

and

$$
\frac{\mathrm{d} C_{\text {nitrite }}}{\mathrm{dt}}=\mathrm{G}_{\text {nitrate }} \cdot \mathrm{E} \cdot \mathrm{C}_{\text {nitrate }}-\mathrm{G}_{\text {nitrite }} \cdot \mathrm{E} \cdot \mathrm{C}_{\text {nitrite }}
$$

where 
$\mathrm{C}_{\text {nitrate }}=$ concentration of nitrate ions,

$\mathrm{C}_{\text {nitrite }}=$ concentration of nitrite ions,

$\mathbf{t}=$ time,

$\mathrm{G}_{\text {nitrate }}=$ rate constant for nitrate decomposition,

$\mathrm{G}_{\text {nitrite }}=$ rate constant for nitrite decomposition, and

$\mathrm{E}=$ rate of energy deposition.

We obtained the rate constants in Eqs. (8) and (9) from data from Tank 241-C-106. ${ }^{21}$ The values of the rate constants are $4.0 \pm 2.4$ molecules $\mathrm{L} / 100 \mathrm{eV}$ mole nitrate for nitrate decomposition and $1.5 \pm 0.5$ molecules $\mathrm{L} / 100 \mathrm{eV}$ mole nitrite for nitrite decomposition. Equations

$\frac{\mathrm{dC}_{\text {nitrate }}}{\mathrm{dt}}=-\mathrm{G}_{\text {nitrate }} \cdot \mathrm{E} \cdot \mathrm{C}_{\text {nitrate }}$

and (9) can be solved to determine the nitrate and nitrite concentrations in the past.

Equation (7) shows that hydroxide ion is formed as a result of nitrite decomposition. The following material balance equation can be used to determine hydroxide concentration in the past:

$$
\left(C_{\text {hydroxide }}+C_{\text {nitrate }}+C_{\text {nitrite }}\right)_{\text {past }}=\left(C_{\text {hydroxide }}+C_{\text {nitrate }}+C_{\text {nitrite }}\right)_{\text {present }} \text {, }
$$

\subsubsection{Calculation of Waste Levels}

The current waste level is the sum of the thicknesses of the NC layer, the $C$ layer, and the crust:

$$
\mathrm{Z}_{\text {waste }}=\mathrm{Z}_{\mathrm{NCL}}+\mathrm{Z}_{\mathrm{CL}}+\mathrm{Z}_{\text {crust }} \text {, }
$$

where

$$
\begin{aligned}
Z_{\text {waste }} & =\text { waste level } \\
Z_{N C L} & =N C \text { layer thickness } \\
Z_{C L} & =C \text { layer thickness, and } \\
Z_{\text {crust }} & =\text { crust thickness. }
\end{aligned}
$$

We assume that there was little gas in the waste when the tank was filled. The initial waste level can be determined from the layer thicknesses on a gas-free basis:

$$
Z_{\text {waste, initial }}=\left(1-\phi_{g, N C L}\right) \cdot Z_{N C L}+\left(1-\phi_{g, C L}\right) \cdot Z_{C L}+\left(1-\phi_{g, \text { crust }}\right) \cdot Z_{\text {crust }} \text {, }
$$

where 


$$
\begin{aligned}
\mathrm{Z}_{\mathrm{waste}, \text { initial }} & =\text { initial waste level, } \\
\phi_{\mathrm{g}, \mathrm{NCL}} & =\text { gas fraction in NC layer, } \\
\phi_{\mathrm{g}, \mathrm{CL}} & =\text { gas fraction in C layer, and } \\
\phi_{\mathrm{g}, \text { crust }} & =\text { gas fraction in crust layer, }
\end{aligned}
$$

\subsubsection{Calculation of Waste Compressibility}

Because gas is stored in the waste, the waste is compressible, and its level will change as a result of changes in the barometric pressure. It is relatively simple to calculate the change in level with barometric pressure if the bubbles are immobile. However, the assumption of immobile bubbles may not apply to the crust and the $C$ layer. Because of this uncertainty, we can compute only upper and lower bounds for the waste compressibility.

A lower bound is calculated by assuming that (1) the bubbles in the NC layer are immobile, (2) the bubbles in the C layer are immobile, and (3) the crust is incompressible. An upper bound estimate is obtained by assuming that (1) the bubbles in the NC layer are immobile, (2) the bubbles in the $C$ layer have maximum mobility, and (3) the crust is compressible.

We constrain our estimates of the gas volume to be consistent with these upper and lower bounds.

\subsection{Gas Generation, Accumulation, and Release Models}

Waste inventory is a common factor underlying the waste tank behavior. Many of the physical properties can be determined from the waste inventory. However, inventory alone cannot explain GREs. A second underlying factor must be considered: gas generation rate. If we establish the gas generation rates, we can determine the gas composition, the rate of level rise, and so forth. In this section, we consider gas generation and models related to gas generation.

Our approach to gas generation and related quantities is similar to the approach we use for waste inventory. We do not calculate gas generation rate from the data. rather, we start with an estimate of the gas generation rate and composition and estimate the values of measured quantities such as background hydrogen concentration and rate of level rise. The maximum likelihood analysis is used to find the inventory that is most consistent with all of the data.

\subsubsection{Generation of Slightly Soluble Gases}

We do not understand gas generation in the waste tanks in the sense that we do not have a mechanistic model capable of accurately predicting the gas generation rate and composition. However, lacking a mechanistic model is not equivalent to being ignorant of the gas generation rates. For example, we know that gas generation is the result of both radiolytic chemical reactions and thermal chemical reactions. 
Experiments show that the mole fraction hydrogen tends to decrease with increasing temperature.

Although we cannot develop a mechanistic model, an empirical model is a useful method of summarizing our limiting understanding of gas generation. Such a model enables us to make estimates of the gas generation rates that are consistent with our understanding of gas generation and to understand how changes to the waste affect gas generation and composition.

We use a simple model of gas generation in our analysis to generate reasonable estimates of the gas generation rate and composition and to incorporate our knowledge of gas generation into the analysis. The model is based on laboratory experiments with simulants and actual waste samples, tank data, and RGS results. The mathematical form of the model is similar to those used by Graves 22 and Hopkins. ${ }^{23}$ This model is based on the assumption that the gas generation rate can be represented as the sum of two terms: generation by radiolytic reactions and generation by thermal (ordinary) chemical reactions. The radiation chemical yield ( $G$ value) is a function of the total organic carbon (TOC) concentration in the liquid. The reaction rates for the thermal reactions are a function of the TOC concentration in the liquid, the concentration of aluminum in the liquid, and temperature. We use two components to model gas generation: hydrogen gas and gaseous nitrogen compounds. The nitrogen compounds include nitrogen and nitrous oxide. Because radiolytic decomposition of nitrous oxide occurs, it is difficult to separate nitrogen generation from nitrous oxide generation. Therefore, we lump nitrogen and nitrous oxide together in the gas generation model. Details of the model are given in Ref. 24. This model should be viewed as a summary of our knowledge rather than as a rigorous quantitative model. The qualitative nature of this model is reflected in the large uncertainties that we assign to the parameter.

\subsubsection{Generation of Ammonia}

We assume that radiolytic decomposition of nitrite ions is the primary mechanism of ammonia generation in AN-105.20 Reactions involving the organic compounds in the waste may be another mechanism for generating ammonia, but we assume that this mechanism is not significant because the concentration of TOC in AN-105 is small.

To estimate the ammonia concentration in the waste, we assume that the rate of ammonia loss is small compared with the ammonia generation rate. Ammonia concentration as a function of time is given by the following differential equation:

$$
\frac{\mathrm{dC}_{\text {ammonia }}}{\mathrm{dt}}=\mathrm{G}_{\text {ammonia }} \cdot \mathrm{E} \cdot \mathrm{C}_{\text {nitrite }} \text {, }
$$

where 


$$
\begin{aligned}
\mathrm{C}_{\text {ammonia }} & =\text { concentration of ammonia, } \\
\mathrm{C}_{\text {nitrite }} & =\text { concentration of nitrite ions, } \\
\mathrm{t} & =\text { time } \\
\mathrm{G}_{\text {ammonia }} & =\text { rate constant for ammonia generation, and } \\
\mathrm{E} & =\text { rate of energy deposition. }
\end{aligned}
$$

We estimate $G_{\text {ammonia }}$ to be $0.32 \pm 0.10$ molecules $\mathrm{L} / 100 \mathrm{eV}$ mole nitrite. ${ }^{25}$ This equation can be solved with Eqs. (8) and (9) to obtain ammonia concentration as a function of time. The waste was processed through a vacuum evaporator before being placed in AN-105, so we assume that it contained very little ammonia when it initially was put into the tank.

\subsubsection{Gas Solubility}

We need to consider vapor-liquid equilibrium to determine the composition of gas bubbles and the concentrations of dissolved gas in the liquid. We use Henry's law to describe the vapor-liquid equilibrium of the gases. The Henry's law constant for the waste is the Henry's law constant in pure water times an activity coefficient. We use a correlation based on the Pitzer equation, ${ }^{26}$ which gives the activity coefficient as a function of ionic strength. There are large uncertainties in this correlation; however, it is consistent with the available literature data.

We do not use Norton and Pederson's data 27 in our analysis. Their data appear to be inconsistent with published hydrogen solubility data. They measure hydrogen solubilities that are much lower than expected based on published data for aqueous electrolytes. We cannot evaluate the validity of their experimental procedure for measuring hydrogen solubility because they did not report any results for aqueous electrolyte solutions that have been published in the literature. Because we cannot verify the experimental procedure, we prefer using a correlation that is consistent with literature data rather than Norton and Pederson's data.

The vapor pressure of water for an aqueous electrolyte solution is the activity of water in the solution time the vapor pressure of pure water. We use the solubility model discussed in Sec. 3.1.2 to calculate the activity of water in solutions. For saltcake wastes, the activity of water is typically between 0.2 and 0.4 .

\subsubsection{Retained Gas Composition}

To calculate the gas composition in the bubbles, we make two assumptions.

- The concentrations of hydrogen, nitrogen, nitrous oxide, and methane have reached steady-state values. This assumption is reasonable because these gases are relatively insoluble.

- The amount of ammonia in the bubbles is a small fraction of the total ammonia inventory in the waste. 
The implication of the first assumption is that the composition on an ammonia and water free bases can be determined from the gas generation rate. The implication of the second assumption is that the partial pressure of ammonia can be determined from the concentration of ammonia in the liquid.

For the slightly soluble gases, the model fraction of component $i$ in a bubble is

$$
y_{i}=x_{i} \cdot\left(1-\frac{P_{\text {ammonia }}-P_{\text {water }}}{P}\right),
$$

where

$$
\mathrm{y}_{\mathrm{i}}=\text { mole fraction } \mathrm{i} \text { in a bubble, }
$$

$x_{i}=$ mole fraction of the insoluble gases generated that is $i$,

$\mathrm{P}_{\text {ammonia }}=$ ammonia partial pressure,

$\mathrm{P}_{\text {water }}=$ water partial pressure, and

$\mathrm{P}=$ total pressure of the bubble.

The partial pressure of ammonia is determined from Henry's law, and the water partial pressure is determined from the activity of water and the partial pressure of pure water.

Analysis of the RGS data gives moles of gas per unit volume of waste. This estimate includes both gas bubbles and dissolved gas. Assuming the ideal gas and Henry's law, the moles of slightly soluble gas i per unit volume of waste are

$$
C_{i}=\frac{\phi_{g} \cdot y_{i} \cdot R \cdot T}{P}+\frac{\phi_{L} \cdot y_{i} \cdot P}{H_{i}}
$$

where

$\mathrm{C}_{\mathrm{i}}=$ mole of $\mathrm{i}$ per unit volume of waste,

$\phi_{\mathrm{g}}=$ volume fraction gas in the sample,

$\mathrm{y}_{\mathrm{i}}=$ mole fraction in the bubble,

$\mathrm{R}=$ gas constant,

$\mathrm{T}=$ waste temperature,

$\mathrm{P}=$ pressure of the bubbles,

$\phi_{\mathrm{L}}=$ volume fraction liquid in the sample, and

$\mathrm{H}_{\mathbf{i}}=$ Henry's law constant for $\mathrm{i}$.

To convert the moles of gas per unit volume of waste in the tank to the RGS results, we must add air entertainment to Eq. (15). 


\subsubsection{Hydrogen Balance in the Dome Space}

We use a steady-state model to estimate the background hydrogen concentration in the dome. We also assume that the ideal gas law applies and the concentration of hydrogen in the air is negligible. The hydrogen balance for the dome is

$$
\frac{P_{\text {dome }} \cdot q_{\text {vent }}}{R \cdot T_{\text {dome }}} \cdot y_{\text {hydrogen }}=n_{\text {hydrogen }},
$$

where

$$
\begin{aligned}
\mathrm{P}_{\text {dome }} & =\text { dome pressure } \\
\mathrm{T}_{\text {dome }} & =\text { dome temperature } \\
\mathrm{q}_{\text {vent }} & =\text { volumetric vent flow rate, } \\
\mathrm{R} & =\text { gas constant } \\
\text { yhydrogen } & =\text { mole fraction hydrogen in the dome, and } \\
\mathrm{n}_{\text {hydrogen }} & =\text { background hydrogen release rate. }
\end{aligned}
$$

To estimate the background hydrogen, release rate we assume that all of the hydrogen generated in the $C$ layer and crust is released as it is generated and a fraction of the gas generated the NC layer is released. The steady-state release from the NC layer is an adjustable parameter in this analysis.

Hydrogen is released through two mechanisms: release of bubbles containing hydrogen, and interfacial mass transfer at the waste surface. The mass-transfer rate cannot exceed the total release rate. We estimate the hydrogen mass-transfer rate to determine if the mass-transfer rate is less than the total release rate. We assume that the C layer is saturated with dissolved gases, and we assume steady-state diffusion through the crust. We consider three resistances in our calculation: liquid-phase resistance, crust resistance, and gas-phase resistance. We use the correlations in Ref. 28 to estimate the mass-transfer coefficients. This restriction of the hydrogen mass-transfer rate is actually a constraint on the crust thickness.

\subsubsection{Rate of Level Rise}

For AN-105, we consider the initial rate of level rise and the current rate of level rise between GREs. We assume that there is no net accumulation of gas in either the C layer or the crust. Therefore, the rate of level rise is a function of the gas accumulation in the NC layer.

$$
\frac{\mathrm{dz}}{\mathrm{dt}}=\mathrm{f}_{\text {retained }} \cdot \mathrm{r}_{\mathrm{gas}} \cdot \phi_{\mathrm{L}} \cdot \mathrm{z}_{\mathrm{nc}} \cdot \mathrm{A} \cdot \frac{\mathrm{R} \cdot \mathrm{T}_{\mathrm{nc}}}{\mathrm{P}_{\mathrm{nc}}},
$$

where

$$
\mathrm{z} \text { = waste level, }
$$




$$
\begin{aligned}
\mathrm{f}_{\text {retained }} & =\text { fraction of gas retained in the NC layer, } \\
\mathrm{r}_{\text {gas }} & =\text { gas generation rate in mole/L liquid } \mathrm{s}, \\
\phi_{\mathrm{L}} & =\text { volume fraction liquid in the NC layer, } \\
\mathrm{z}_{\mathrm{nc}} & =\text { thickness of the NC layer } \\
\mathrm{A} & =\text { waste tank area, } \\
\mathrm{R} & =\text { gas constant, } \\
\mathrm{T}_{\mathrm{nc}} & =\text { average } \mathrm{NC} \text { layer temperature, and } \\
\mathrm{P}_{\mathrm{nc}} & =\text { average NC layer pressure. }
\end{aligned}
$$

To calculate the initial rate of level rise, we assume that all the gas generated is retained by the NC layer. The creep model of the gas fraction distribution indicates that most of the gas is retained initially. ${ }^{29}$ We solve the solubility model at the initial waste temperature to determine the liquid fraction and liquid composition in the NC layer at the initial waste temperature. We then use the gas generation model to estimate the gas generation rate at the initial waste temperature.

At the current time, we do not know whether there is a steady-state release of gas bubbles from the NC layer. Therefore, we treat the fraction of gas retained in the NC layer as an unknown parameter. We determine the liquid fraction, liquid composition, and rate of gas generation from the current, in situ conditions.

\subsubsection{Gas Release Events}

The Rayleigh-Taylor model of GREs was used to describe the large-scale GREs observed in Tank 241-SY-101. In this model, gas is assumed to accumulate in the NC layer, which reduces the bulk density of the layer. Gas accumulates until the density of the NC layer is less than that of the C layer. The resulting instability causes large-scale mixing in the tank and the release of a large fraction of the retained gas.

The Rayleigh-Taylor model of GREs does not fully explain the behavior of Tank AN-105. The temperature profile data indicate that mixing of the NC layer occurs during a GRE, but only a part of the layer participates in a given GRE. In this study we make no attempt to model this behavior. Instead, we attempt to bound GREs.

The first bounding model that we consider is used to determine the maximum amount of gas that can be released given the current retained gas inventory. We assume that the entire NC layer participates in the GRE. For gas bubbles, we assume that only the fraction of the gas stored in excess of $1.0 \mathrm{~atm}$ can be released. Dissolved gas will be released until the bubble-point pressure decreases to $1.0 \mathrm{~atm}$. We use this model as an inequality constraint in our data reconciliation. The level drop for this bounding GRE must be greater than the largest observed level drop.

We use the second bounding model to evaluate what would happen if a change occurred that would cause the NC layer to retain more gas; we use the RayleighTaylor model to determine the maximum possible gas fraction in the NC layer. The 
maximum gas fraction is the fraction for which the bulk density of the NC layer equals the density of the $C$ layer. We use the release model described above to determine the maximum fraction of the retained gas that is released.

\subsection{METHOD OF ANALYSIS}

\subsection{Maximum Likelihood Data Reconciliation}

If we assume that the errors in the measurements and the uncertainty in the model parameters are statistically independent and that they follow a normal distribution, the maximum likelihood method is equivalent to solving the following minimization problem:

$$
\begin{gathered}
\min _{\mathbf{x}, \mathbf{p}, \theta} \sum_{i}\left(\frac{x_{i}-x_{i}}{\sigma_{X_{i}}}\right)^{2}+\sum_{j}\left(\frac{p_{j}-P_{j}}{\sigma_{P j}}\right)^{2} \\
\text { subject to } \quad \begin{array}{l}
\mathbf{f}(\mathbf{x}, \mathbf{p}, \theta)=0 \text { and } \\
\mathbf{g}(\mathbf{x}, \mathbf{p}, \theta) \geq 0
\end{array}
\end{gathered}
$$

where

$$
\begin{aligned}
x_{i} & =\text { maximum likelihood estimate of measurement } i \\
X_{i} & =\text { measurement } i \\
\sigma_{X_{i}} & =\text { standard deviation of measurement } i \\
p_{j} & =\text { maximum likelihood estimate of parameter } j, \\
P_{j} & =\text { previous estimate of parameter } j \\
\sigma_{P_{j}} & =\text { standard deviation of previous estimate of parameter } j, \text { and } \\
\theta & =\text { vector of parameters with no previous estimates. }
\end{aligned}
$$

An example of a parameter with a previous estimate is the G-value for radiolysis of water in the waste. Although this parameter has been measured in the laboratory, there is experimental error associated with the measurement. An example of a parameter with no previous estimate is the fraction of the total hydrogen released during a GRE that originates as bubbles in the NC layer. The functions $\mathbf{f}(\mathbf{x}, \mathbf{p}, \theta)$ and $\mathbf{g}(\mathbf{x}, \mathbf{p}, \theta)$ represent the model and are included in the analysis as constraints. The maximum likelihood method is discussed in greater detail in Ref. 1.

The parameters for which there are previous estimates are the gas generation model parameters, activity coefficient model parameters, error in Henry's law constants, mass-transfer coefficients, and diffusion coefficient for hydrogen. Parameters for which there are no prior estimates are the solubility product for sodium aluminate, 
the plutonium solubility, the molecular weight of the heavy salts, and the density of heavy salts. To ensure that the values of molecular weight and density of the heavy salts are realistic, we constrain the molecular weight to values between $70 \mathrm{~g} / \mathrm{mole}$ and $250 \mathrm{~g} / \mathrm{mole}$ and the density to values between $2.3 \mathrm{~g} / \mathrm{cm}^{3}$ and $9.0 \mathrm{~g} / \mathrm{cm}^{3}$.

The maximum likelihood estimates of the measured values and parameters are obtained by solving the minimization problem. We used Microsoft Excel for our analysis and solved the minimization problem using the Solver routine in Excel.

The maximum likelihood data reconciliation of Tank 241-AN-105 is a nonlinear problem. A Monte Carlo method is the only means of performing a rigorous uncertainty analysis for this problem. However, because a Monte Carlo calculation requires a great deal of time, it is not practical. Therefore, we use an approximate method to estimate the uncertainty in safety-related parameters that are of interest. First, we use judgment to identify the most important sources of uncertainty. Next, we use one of three methods to estimate the uncertainty.

- If the data are redundant, we use an approximate maximum likelihood analysis to estimate uncertainty.

- If the data are not redundant, we use a linear propagation of errors or Monte Carlo calculation to estimate uncertainty.

- We disregard redundancies in the data and use a linear propagation of errors or Monte Carlo calculation to obtain a conservative-estimate uncertainty.

\subsection{Gas-Release Event Statistics}

The maximum likelihood analysis is based on static models that cannot be used to estimate the frequency of GREs or the distribution of gas release volumes. Assuming that the gas release mechanisms do not change, we can estimate frequencies from the available GRE data.

The frequency of GREs can be determined easily by dividing the number of events observed in a given time interval by the duration of the time interval. We do not evaluate a probability distribution for the period between GREs. The SHMS in AN105 have only been operational since September 1994, so we base our analysis on the distribution of level drops. Because all significant level drops that we have identified may not be GREs, determining the frequencies of GREs from level drop will be conservative.

In determining the distribution for level drops, we considered five possible distributions: normal, log-normal, three-parameter log-normal, two-parameter Weibull, and three-parameter Weibull. We determined the parameters and quality 
of fit for each type of distribution. We defined the "best" distribution to be the one that gave a reasonable fit of the data and the most conservative extrapolations.

\subsection{RESULTS}

\subsection{Results of the Maximum Likelihood Analysis}

We found that we could reconcile the data within experimental errors. Based on $\chi^{2}$ statistics, the expected value for the weighted sum of the residuals squared is 36 . The lower bound of the $95 \%$ confidence interval is 25 , and the upper bound is 56 . The maximum likelihood analysis gives a value of 45 . Because the calculated weighted sum of the residuals squared is not significantly different from the expected value, we conclude that data have been reconciled within experimental errors. The results of our data reconciliation for this case are summarized in

Table VII under the heading "Current Values."

We used the results of the data reconciliation to develop two release scenarios, which are based on the bounding models described in Sec. 3.27.

- Scenario 1-A worst-case release of the current gas inventory in the tank. This case represents a bounding analysis of the current tank conditions.

- Scenario 2-A worst-case rollover with the steady-state gas composition. This case represents a large release assuming the maximum possible gas inventory.

These two scenarios are hypothetical in the sense that they do not represent the observed waste behavior. However, they are difficult to disprove with a high degree of confidence, and thus, they must be considered for safety analysis purposes. These results are given in Table VIII. Stewart et al. ${ }^{8}$ give a best-estimate value of $5200 \mathrm{scf}$ for the gas bubble inventory in the NC layer. This estimate is within $2.0 \mathrm{std} \mathrm{dev}$ of the best-estimate value for Scenario 1, which represents the current tank conditions.

\subsection{Gas-Release Event Statistics}

We found that the frequency of a GRE in Tank $241-\mathrm{AN}-105$ is $~ 1.9 / \mathrm{yr}$. We also found that the log-normal distribution gave the best fit and the most conservative extrapolations. The median level drop from this distribution is 1.2 in. Assuming that all of the flammable gas is released from the NC layer, the probability of exceeding $25 \%$ of the lower flammability limit (LFL) during a GRE is 0.63 ; and the 
TABLE VII

RESULTS OF THE MAXIMUM LIKELIHOOD DATA RECONCILIATION FOR

TANK 241-AN-105

\begin{tabular}{|c|c|c|c|c|}
\hline \multirow{2}{*}{ Parameter } & \multicolumn{2}{|c|}{ Current Values } & \multicolumn{2}{|c|}{ Bounding Values } \\
\hline & $\begin{array}{c}\text { Best } \\
\text { Estimate }\end{array}$ & Std Dev & $\begin{array}{c}\text { Best } \\
\text { Estimate }\end{array}$ & Std Dev \\
\hline C Layer Density $\left(\mathrm{g} / \mathrm{cm}^{3}\right)$ & 1.42 & 0.04 & 1.42 & 0.04 \\
\hline NC Layer Density $\left(\mathrm{g} / \mathrm{cm}^{3}\right)$ & 1.60 & 0.03 & 1.60 & 0.03 \\
\hline NC Layer Gas Fraction (vol \%) & 3.2 & 0.3 & 11.3 & 3.0 \\
\hline $\mathrm{H}_{2}$ in NC Layer Bubbles (mole \%) & 57 & 6 & 57 & 6 \\
\hline $\mathrm{NH}_{3}$ in Liquid (mole/L) & 0.12 & 0.03 & 0.12 & 0.03 \\
\hline $\mathrm{NH}_{3}$ Partial Pressure (atm) & 0.010 & 0.001 & 0.010 & 0.001 \\
\hline Total Gas Bubble Inventory (scfa) & 4400 & 400 & 16600 & 440 \\
\hline Total $\mathrm{H}_{2}$ Inventory (scf) & 2500 & 400 & 9600 & 2800 \\
\hline NC LayerGas Generation Rate (scf/day) & 1.2 & 0.1 & 1.2 & 0.1 \\
\hline Total GasGeneration Rate (scf/day) & 3.0 & 0.3 & 3.0 & 0.3 \\
\hline
\end{tabular}

aStandard conditions are $1 \mathrm{~atm}$ pressure and in situ waste temperature.

probability of exceeding $100 \%$ of the LFL is 0.0043 . The frequency of exceeding $25 \%$ of the LFL is $1.2 / \mathrm{yr}$, and the frequency of exceeding $100 \%$ of the LFL is $8 \times 10^{-3} / \mathrm{yr}$. The estimate of the frequency of exceeding LFL is based on the probability distribution that gave the most conservative extrapolation of the data.

\subsection{DISCUSSION OF RESULTS}

The data for Tank AN-105 are reasonably consistent, but it is difficult to explain the observed GRE behavior. The Rayleigh-Taylor instability model is used to explain GREs in SY-101. However, it is problematic for AN-105. Temperature profile data indicate that mixing of the NC layer occurs, but the data indicate that gas fraction in the NC layer is much less than that needed to produce an instability. The neutral buoyancy point in AN-105 corresponds to a gas fraction of $11 \pm 6 \mathrm{vol} \%$ in the NC layer. The average gas fraction in $\mathrm{NC}$ layer is $3.2 \mathrm{vol} \%$ and the maximum gas fraction measured with the void fraction instrument is $6.7 \mathrm{vol} \%$.

The void fraction instrument was only deployed in two risers. There may be regions with locally high gas fractions at other location. The RGS results indicate that this may be the case. One RGS core segment had a void fraction of 13.3 vol. \%.7 The thermal balance calculations summarized in Sec. 2.8 indicate that $\sim 25 \%$ of the NC layer participates in a GRE. If $25 \%$ of the NC layer were at the neutral buoyancy point and a portion of the waste participated in a GRE, the observed level drop would be $2.8 \mathrm{in}$. This estimate is comparable to the maximum observed level drop given in Table $\mathrm{V}$. 
TABLE VIII

BOUNDING GAS RELEASE SCENARIOS FOR TANK 241-AN-105

\begin{tabular}{|l||c|c||c|c|}
\hline \multicolumn{1}{|c||}{ Parameter } & \multicolumn{2}{c||}{ Scenario 1 } & \multicolumn{2}{c|}{ Scenario 2 } \\
\cline { 2 - 5 } & $\begin{array}{c}\text { Best } \\
\text { Estimate }\end{array}$ & $\begin{array}{c}\text { Std } \\
\text { Dev }\end{array}$ & $\begin{array}{c}\text { Best } \\
\text { Estimate }\end{array}$ & $\begin{array}{c}\text { Std } \\
\text { Dev }\end{array}$ \\
\hline Waste Level (in.) & 411.6 & 1.0 & 427 & 6 \\
Gas Frac. in NC Layer (\%) & 3.2 & 0.3 & 11.3 & 3.0 \\
Total $\mathrm{H}_{2}$ Inventory (scf) & 2500 & 400 & 9600 & 2800 \\
$\mathrm{H}_{2}$ in NC Layer (scf) & 2500 & 400 & 9600 & 2800 \\
Releasable H2 (scf) & 1500 & 200 & 5300 & 1600 \\
$\mathrm{H}_{2}$ in the Dome following a & 2.2 & 0.3 & 10.7 & 3.2 \\
$\begin{array}{l}\text { GRE (mole \%) } \\
\text { NH } \\
\text { GRE (mole \%) }\end{array}$ & 1.0 & 0.1 & 1.0 & 0.1 \\
\hline
\end{tabular}

A partial rollover or other buoyant displacement model can explain the GREs in AN-105. Because of the low gas generation rate in AN-105, we expect that there is significant migration of gas out of the upper layers of the NC layer. ${ }^{29}$ The void fraction instrument results support our expectations. 8 A buoyant pocket of waste will form near the bottom of the NC layer. A release of a buoyant pocket of gas will disturb the upper layers of the NC layer. Therefore, we expect that a GRE that disturbs $25 \%$ of the NC layer will result in level drops $<2.8$ in., which is what is observed in AN-105.

It also is instructive to compare the behavior of AN-105 with Tank 241-AW-101 (AW-101). SHMS data indicate that there are frequent small releases that do not correlate with level drop. ${ }^{10}$ Temperature data indicate that mixing of the NC layer does not occur during GREs. We postulated episodic releases of dissolved gases from the C layer to explain small GREs that do not correlate well with level. ${ }^{30} \mathrm{We}$ ask the question, "Why are releases of dissolved hydrogen from the $C$ layer not observed in AN-105?" The answer is differences in waste composition.

We estimate that the solids in AW-101 are $87 \mathrm{wt} \%$ sodium nitrate. The remaining components in the solids are sodium carbonate, sodium oxalate, sodium sulphate, and insoluble salts. The density of a saturated sodium nitrate solution increases 
with temperature $\left[\left(\partial \rho_{\mathrm{L}} / \partial \mathrm{T}\right)_{\mathrm{satd}} .>0\right]$ because the solubility of sodium nitrate increases with temperature. The increase in saturated liquid density with temperature results in a stable density profile, which is a necessary condition for episodic releases of dissolved gas. The solids composition in AN-105 is very different from AW-101. The solids are $70 \mathrm{wt} \%$ sodium carbonate in the unhydrated form. The remaining solids components are insoluble salts, sodium oxalate, and the unhydrated form of sodium sulphate. The solubility of the unhydrated forms of sodium carbonate and sodium sulphate decrease with increasing temperature. The lack of solids in the C layer samples at ambient temperature is consistent with our estimates of the solids composition. Because solubility decreases with increasing temperature, $\left(\partial \rho_{\mathrm{L}} / \partial \mathrm{T}\right)_{\text {satd }}<0$; therefore, natural convection occurs in the $\mathrm{C}$ layer. Episodic releases of dissolved gas are not possible if natural convection occurs.

As noted above, mixing of the NC layer occurs during GREs in AN-105, but no NC layer mixing has been observed in AW-101. There are no obvious differences in densities, viscosity, or yield strength to explain this difference in NC layer mixing. The solids composition is an obvious difference, but we have no theory to relate solids composition to gas retention and release behavior.

Finally, we consider the initial gas fraction in the waste. In our analysis of AW-101, we concluded that air was entrained in the waste when the tank was filled. ${ }^{30} \mathrm{We}$ did not consider air entertainment during filling in this study. We do not discount the possibility of air entertainment during filling, but we did not need to consider it in our analysis for two reasons. First, small amounts of entrained air in AN-105 are not expected to have a significant effect of the waste material balances. We only postulated that the NC layer of AW-101 contained $\sim 2 \mathrm{vol} \%$ of entrained air when it was filled. Second, we do not expect that significant amounts of entrained air remain in AN-105 because mixing of the NC layer during GREs should have released any entrained air.

\subsection{CONCLUSIONS}

Our review and analysis of the data from Tank 241-AN-105 indicate that flammable gases are released from the waste as a result of partial rollovers or some other buoyant displacement mechanism. Flammable gas concentrations in the dome in excess of the LFL may be possible. The current flammable gas inventory given in Table VIII represents the average inventory in the tank. The average inventory does not pose a flammable gas hazard. However, the observed variability in waste level about the mean indicates variability in gas inventory. The variability is large enough that there are times when the tank contains sufficient flammable gas to pose a hazard. However, if no significant changes occur, concentrations in excess of the LFL are unlikely. Based on GRE data, the frequency of exceeding LFL is $<0.008 / \mathrm{yr}$.

The lack of global rollovers in Tank 241-AN-105 makes it qualitatively different from Tank 241-SY-101. We believe that the gas generation rate may be one factor 
accounting for this difference. For a global rollover to occur, the gas generation rate in the NC layer must exceed the rate at which gas migrates out of the layer. The data indicate that the gas generation rate in Tank 241-AN-105 is much less than that in Tank 241-SY-101. The total gas generation rate in Tank 241-SY-101 is $~ 120 \mathrm{scf} /$ day, which is 40 times greater than the generation rate in Tank 241-AN-105. We believe that two factors account for the lower gas generation rate in Tank 241-AN-105: a lower waste temperature and a lower TOC concentration in the liquid. Although the temperature data indicate that fluctuations and oscillations occur, there is no indication of a significant temperature increase in Tank 241-AN-105. Because no waste is being added to this tank, the TOC concentration cannot increase. We do not expect a significant increase in the gas generation rate, and thus, we do not expect a qualitative change in the behavior of Tank 241-AN-105.

If a qualitative change occurs in Tank 241-AN-105 and buoyancy-driven rollovers begin to occur, large GREs are possible. We estimate the maximum dome hydrogen concentration in the event of a rollover to be 11 mole $\%$, which is $270 \%$ of the LFL. The standard deviation for this estimate is 3 mole \%. However, such a change would be accompanied by a measurable increase in waste level. Based on the current gas generation rate, the change would be slow.

There must be a significant increase in the retained gas inventory in Tank 241-AN105 before a rollover is possible. A significant increase in the retained gas inventory would result in a measurable increase in the level of the waste surface. To reach the neutral buoyancy condition, the level must increase $\sim 12$ in. This conclusion is independent of our speculation concerning the differences between Tank 241-AN105 and Tank 241-SY-101. Based on the current rate of gas generation, it will take $\sim 20 \mathrm{yr}$ to reach the neutral buoyancy condition. Approximately $6 \mathrm{yr}$ would be required for the average gas fraction in the NC layer to increase to $11 \mathrm{vol} \%$.

To summarize, we believe that a release of a flammable quantity of hydrogen in Tank 241-AN-105 is possible but unlikely at the current time. Any changes to the waste that could cause large releases would be accompanied by a measurable increase in the surface level of the waste. We also theorize that a significant increase in the waste temperature may signal a qualitative change in the behavior of the waste and an increase in the flammability hazard. 


\section{REFERENCES}

1 W. Kubic, "Maximum Likelihood Reconciliation of Tank 241-SY-101 Data," Los Alamos National Laboratory letter report TSA-10-GLR-95-001 (September 1995).

2 W. Kubic, "Summary, Review, and Analysis of Data for Tank 241-A-101," Los Alamos National Laboratory calc-note TSA10-CN-WT-SA-DA-001, Rev. 0 (January 17, 1996).

3 W. Kubic, "Maximum Likelihood Data Reconciliation for the Retained Gas Sampler Data from Tank 241-AW-101," Los Alamos National Laboratory calcnote TSA10-CN-WT-SA-DA-004 (April 1997).

4 H. Brager, "Summary of Information on Flammable Gas Watch List Tanks," Westinghouse Hanford Company report WHC-EP-0711 (January 1994).

5 C. Brevick, L. Gaddis, and S. Consort, "Supporting Documentation for the Historical Tank Content Estimate for AN Tank Farm, Westinghouse Hanford Company report WHC-SD-WM-ER-314 (September 1995).

6 J. Jo, "Tank Characterization Report for Double-Shell Tank 241-AN-105," Lockheed Martin Hanford Corp. report HNF-SD-WM-ER-678 Rev. 0 (August 1997).

7 A. Sheckarriz, D. Rector, L. Mahoney, M. Chieda, J. Bayes, R. Bauer, N. Cannon, B. Hey, C. Linsschooten, F. Reitz, and E. Siciliano, "Preliminary Retained Gas Sampler Results for Hanford Waste Tanks 241-AN-105, 241-A-101, 241-AN-105, 241-AN-104, and 241-AN-103," Pacific Northwest National Laboratory report PNNL-11450 (December 1996).

8 C. Stewart, J. Alzheimer, M. Brewster, G. Chen, R. Mendoza, H. Reid, C. Shepard, and G. Terrones, "In Situ Rheology and Gas Volume in Hanford Double-Shell Waste Tanks," Pacific Northwest National Laboratory report PNNL-11296 (September 1996).

9 J. Abbott and C. Unal, "Sampling Ability of the In Situ Voidmeter Instrument," Los Alamos National Laboratory letter report TSA-6-94-316 (November 16, 1994).

10 N. Wilkins, "Results of Gas Monitoring of Double-Shell Flammable Gas Watch List Tanks," Westinghouse Hanford Company report WHC-SD-WM-TI-682 Rev. 1 (September 25, 1996). 
11 R. Weast, Handbook of Chemistry and Physics, 53rd Ed., The Chemical Rubber Co., Cleveland (1972).

12 W. Kubic, "Estimating Entrained Air Volumes for the Retained Gas Samples from Tank 241-AW-101," Los Alamos National Laboratory calc-note TSA10-CNWT-SA-DA-005 (May 1997).

13 J. Person, "Effects of Oxygen Cover Gas and $\mathrm{NaOH}$ Dilution on Gas Generation in Tank 241-SY-101 Waste," Westinghouse Hanford Company report WHC-SDWM-DTR-043, Rev. 0 (May 1996).

14 W. Kubic, "Identifying Gas Release Events in the AN Tank Farm at the Hanford Site," Los Alamos National Laboratory letter report (August 1997).

15 R. Crowe, D. Reynolds, and R. van Vleet, "Technical Basis for Selection of Tank 101-SY Intrusion Window," Westinghouse Hanford Company report WHC-SDWM-TI-458 Rev. 3 (July 1992).

16 P. Whitney, "Screening the Hanford Tanks for Trapped Gas," Pacific Northwest Laboratory report PNL-10821 (October 1995).

17 W. Kubic, "Solubility of Salts in High-Level Nuclear Waste," Los Alamos National Laboratory calc-note TSA10-CN-WT-SA-CH-003 (August 26, 1996).

18 V. S. Patwardhan and A. Kumar, "Thermodynamic Properties of Aqueous Solutions of Mixed Electrolytes: A New Mixing Rule," AIChE Journal 39: 711714 (1993).

19 L. H. Sullivan, "A Safety Assessment for Proposed Pump Mixing Operations to Mitigate Episodic Gas Releases in Tank 241-SY-101: Hanford Site, Richland Washington," Los Alamos National Laboratory report LA-UR-92-3196 Rev. 14 (April 1995).

20 S. Agnew, "Hanford Tank Chemical and Radionuclide Inventories: HDW Model, Rev. 4," Los Alamos National Laboratory report LA-UR-96-3860 (January 1997).

21 W. Kubic, "Gas Generation Rates and Compositions for Project W-320," Los Alamos National Laboratory calc-note TSA10-CN-WT-W320-013 (April 1997).

22 R. Graves, "Topical Report on Flammable Gases in Non-Burping Waste Tanks," Westinghouse Hanford Company report WHC-SD-WM-SARR-015 Rev. 0 (June 30, 1994). 
23 J. D. Hopkins, "Criteria for Flammable Gas Watch List Tanks," Westinghouse Hanford Company report WHC-EP-0702, Rev. 0 (August 1994).

24 W. Kubic, "Summary, Review, and Analysis of Data for Tank 241-S-109," Los Alamos National Laboratory draft calc-note TSA10-CN-WT-SA-DA-003, Rev. 0 (December 9, 1996).

25 W. Kubic, "Ammonia and Dissolved Gases for Project W-320," Los Alamos National Laboratory calc note TSA10-CN-WT-W320-012 (1997).

26 W. Kubic and A. McLain, "Estimating Henry's Law Constants for Gases in 101-SY Waste," Los Alamos National Laboratory calc-note TSA6-CN-WT-SA-GR-014 (March 1994).

27 J. Norton and L. Pederson, "Solubilities of Gases in Simulated Tank 241-SY-101 Wastes," Pacific Northwest Laboratory report PNL-10785 (September 1995).

28 D. Mackay and A. Yeun, "Mass Transfer Coefficient Correlations for Volatilization of Organic Solutes from Water," Environ. Sci. Technol 17, 211-217 (1983).

29 W. Bohl, "Remarks on Void Development in Hanford Double-Shell-Tank Sludge," Los Alamos National Laboratory report LA-UR-97-3823 (September 1997).

30 W. Kubic, "Data Reconciliation Study of Tank 241-AW-101 at the Hanford Site," Los Alamos National Laboratory report LA-UR-97-22142 (1997). 